\title{
Evaluation of Children and Adolescents with Thyroid Nodules: A Single Center Experience
}

\author{
(1) Selin Elmaoğulları1, (D) Şervan Özalkak¹, (D) Semra Çetinkaya1, (D) ibrahim Karaman², (D) Çiğdem Üner³, (1) Nilüfer Arda4, \\ (D) Şenay Savaş-Erdeve1, (1) Zehra Aycan1,5
}

\begin{abstract}
1 University of Health Sciences Turkey, Ankara Dr. Sami Ulus Children's Training and Research Hospital, Clinic of Pediatric Endocrinology, Ankara, Turkey

2University of Health Sciences Turkey, Ankara Dr. Sami Ulus Children's Training and Research Hospital, Clinic of Pediatric Surgery, Ankara, Turkey 3 University of Health Sciences Turkey, Ankara Dr. Sami Ulus Children's Training and Research Hospital, Clinic of Pediatric Radiology, Ankara, Turkey ¿University of Health Sciences Turkey, Ankara Dr. Sami Ulus Children's Training and Research Hospital, Clinic of Pediatric Pathology, Ankara, Turkey ${ }^{5}$ Ankara University Faculty of Medicine, Department of Pediatric Endocrinology, Ankara, Turkey
\end{abstract}

\section{What is already known on this topic?}

Thyroid nodules in children have high potential for malignancy (22-26\%). Sonographic findings, such as parenchymal heterogeneity, hypoechogenicity, irregular margins, increased intranodular blood flow, presence of microcalcifications and abnormal cervical lymph nodes increase the likelihood of malignancy. Even nodules $<1 \mathrm{~cm}$ diameter associated with risk factors require fine needle aspiration biopsy.

\section{What this study adds?}

The malignancy rate in this relatively small cohort of children and adolescents with thyroid nodules was $10 \%$. Patients with atypia of undetermined significance/follicular lesion of undetermined significance on fine needle aspiration (FNA) had $9 \%$ potential for malignancy. In addition, patients with initially benign FNA result had later changes, giving a $5.3 \%$ false negative rate.

\begin{abstract}
Objective: We aimed to evaluate the clinical, radiological and pathological findings of children and adolescents with thyroid nodules. Methods: Data of 121 children and adolescent with thyroid nodules and had fine needle aspiration (FNA) were examined retrospectively. Concomitant thyroid disease, ultrasonography (US) features of the nodule, FNA and histopathological results were recorded. FNA results were assessed according to The Bethesda System for Reporting Thyroid Cytopathology (TBSRTC).

Results: Median (range) age of the cases was 14 (3-18) years and $81 \%$ were female. FNA results of patients were: insufficient in $1(0.8 \%)$; benign in 68 (56.2\%); indeterminate in 44 (36.4\%); and malignant in 8 (6.6\%) patients. Among 39 patients who underwent surgery, $10(25.6 \%)$ had differentiated thyroid cancer (DTC) and the overall malignancy rate was $10.0 \%$ (10/100). Follow-up FNA results showed progress based on TBSRTC in $18.7 \%$ of benign results and 4/75 patients had DTC on surgical excision. Two of 22 patients with atypia of undetermined significance (AUS) who continued follow-up was diagnosed with DTC. Male gender, presence of Hashimoto thyroiditis and US findings of uninodularity, hypoechogenicity, increased blood flow, irregular margins, solid structure, microcalcification and presence of abnormal cervical lymph nodes were associated with malignancy.

Conclusion: In this study $10 \%$ of thyroid nodules were malignant in children and adolescents. Patients with AUS have a $9 \%$ potential for malignancy. Patients with initially benign FNA result may have changes on repeat FNA when assessed with TBSTRC indicating a $5.3 \%$ false negative rate.
\end{abstract}

Keywords: Adolescents, children, fine needle aspiration, thyroid nodule

Address for Correspondence: Selin Elmaoğulları MD, University of Health Sciences Turkey, Ankara Dr. Sami Ulus Children's Training and Research Hospital, Clinic of Pediatric Endocrinology, Ankara, Turkey Phone: +90 5325808862 E-mail: ekerbicerselin@yahoo.com ORCID: orcid.org/0000-0003-4879-7859
Conflict of interest: None declared Received: 07.09.2020 Accepted: 20.12 .2020

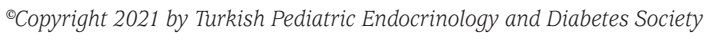

The Journal of Clinical Research in Pediatric Endocrinology published by Galenos Publishing House. 


\section{Introduction}

Thyroid nodule is a lesion characterized by focal abnormal overgrowth of thyroid cells within thyroid tissue. They are usually detected and of clinical importance when noted by the patient, by a clinician during routine physical examination, or during radiologic procedures. Prevalence of thyroid nodules depends on many factors including age, sex, iodine sufficiency status and therapeutic and environmental radiation exposure. Autoimmune thyroiditis, which affects $2-15 \%$ of the population, is also associated with increased risk of nodule formation and thyroid malignancy (1). However, there is no identifiable risk factor present in the majority of patients with thyroid nodules (2).

Thyroid nodules are less common in children (1-1.5\%) and adolescents (up to $13 \%$ ) compared to adults (19-68\%) $(3,4)$. Although most thyroid nodules are benign, the thyroid gland is more susceptible to irradiation and carcinogenesis in children and the risk of malignancy in thyroid nodules is higher in childhood versus adulthood (22-26\% versus $7-15 \%)(5,6,7)$. Therefore, thyroid nodules in children should be investigated carefully, regardless of whether the patient is symptomatic or asymptomatic.

Nodules that warrant fine needle aspiration (FNA) biopsy are identified based on characteristics determined by ultrasonography (US) and clinical context. The American Thyroid Association (ATA) recommends US-guided FNA for thyroid nodules over $1 \mathrm{~cm}$ or $<1 \mathrm{~cm}$ with concerning ultrasonographic features that include hypoechogenicity, irregular margins, increased intranodular blood flow, microcalcifications and abnormal cervical lymph nodes although hyperfunctioning nodules should be excepted from FNA as they require surgery directly (8). Cyopathology findings are categorized by The Bethesda System for Reporting Thyroid Cytopathology (TBSRTC) as nondiagnostic, benign, atypia of undetermined significance/ follicular lesion of undetermined significance (AUS/FLUS), follicular neoplasm/suspicious for follicular neoplasm (FN/ SFN), suspicious for malignancy (SFM), and malignant (9). Further treatment plan is structured, based on TBRSTC category, as intermittent follow-up with US, repeat FNA or surgery.

The aim of this study was to evaluate the clinical, radiological and pathological findings of children and adolescents with thyroid nodules who were followed-up in our clinic.

\section{Methods}

Children and adolescents who were followed up with thyroid nodules and underwent FNA between January
2010 and June 2019 were included in the study and their files were examined retrospectively. Normal serum levels of laboratory tests were accepted as: thyroid stimulating hormone (TSH): 0.6-5.5 $\mathrm{IU} / \mathrm{mL}$; free thyroxine (fT4): 0.8 $1.9 \mathrm{ng} / \mathrm{dL}$; free tri-iodothyronine (fT3): $2-6.5 \mathrm{pg} / \mathrm{mL}$; thyroid peroxidase antibody (anti-TPO): 0-60 IU/mL; thyroglobulin antibody (anti-TG): 0-60 IU/mL; calcitonin: 2-11.5 pg/mL; and thyroglobulin: 0-60 ng/mL. Thyroid function tests (TFTs) at the time of diagnosis were grouped as euthyroid (normal TSH and fT4 levels), subclinical hypothyroidism (TSH: 5.6-9.9 $\mu \mathrm{IU} / \mathrm{mL}$ and normal fT4 levels), hypothyroidism (TSH $\geq 10.0$ $\mu \mathrm{IU} / \mathrm{mL}$ with normal or subnormal fT4 levels), subclinical hyperthyroidism (TSH $<0.6$ with normal fT4 and fT3 levels) and hyperthyroidism (TSH $<0.6$ with fT $4>1.9 \mathrm{ng} / \mathrm{dL}$ or fT3 $>6.5 \mathrm{pg} / \mathrm{mL}$ ). The presence of congenital hypothyroidism, Hashimoto's thyroiditis (HT) or Graves' disease was also noted. Patients with sonographic changes in thyroid gland, such as decrease in parenchymal echogenicity, irregularity, heterogeneity or nodular appearance, in addition to being positive for anti-TPO anti-TG were considered to have HT (10). In patients with subclinical hyperthyroidism or hyperthyroidism, Graves thyroiditis was considered if TSH receptor antibody was positive (11).

US and FNA of all cases were performed by experienced radiologists. Thyroid gland parenchymal structure (homogeneous, heterogeneous); number of nodules (single, multiple); size (largest 3-dimensional measurement); structure (solid, semisolid, cystic); echogenicity (hyperechoic, isoechoic, hypoechoic); characteristics of the margin (regular, irregular, lobulated) and the presence of calcification were examined. FNA was performed with a 22-gauge needle on a 10-mL injector. Three or four samples were taken (from the largest nodule with the highest risk for malignancy, if there were multiple nodules) in each process. Patients were discharged after ensuring hemostasis by US.

FNA and post-thyroidectomy tissues were evaluated by experienced pathologists. FNA specimens were categorized according to TBSRTC (9). In all cases with nondiagnostic results, FNA was repeated. Benign results were followed every six months and FNA was repeated if there was any change in the nature and size of the nodule. The decision to perform surgery for further categories (AUS/FLUS, FN/SFN, SFM and malignant) was made by an expert multidisciplinary council, consisting of pediatric endocrinologists, a pediatric surgeon, a pediatric oncologist, a radiologist and a pathologist.

\section{Statistical Analysis}

Statistical Package for the Social Sciences, version 22 (IBM Inc., Chicago, IL, USA) program was used for statistical analysis. Results were expressed as mean \pm standard 
deviation for parametric data and median + range for nonparametric data. Chi-square test or Fisher Exact test was used for comparing non-numeric data according to minimum expected value. Independent samples median test was used for comparison of non-parametric numerical data medians. Significance level was accepted as $p<0.05$.

\section{Ethics}

This study was approved by the Dr. Sami Ulus Children Training and Research Hospital Specialty and Training Review Board with the decision number 2019/12. The need to obtain informed consent from the study participants was waived due to the study's retrospective nature.

\section{Results}

One hundred and twenty-one cases with thyroid nodules were included in the study. Mean age of the patients was $13 \pm 3$ years (3.4-18 years) and $81 \%$ of them were female (Figure 1). The thyroid US that detected the thyroid nodule(s) was performed because $78(64.4 \%)$ of the patients had enlarged thyroid gland by inspection or palpation. In addition patients with detected nodules were being followed up for HT ( $n=23 ; 19 \%)$, congenital hypothyroidism $(n=4 ; 3.3 \%)$ and Graves' disease $(n=2 ; 1.7 \%)$. Furthermore, $11(9.1 \%)$ patients had defects in TFTs, two (1.7\%) had a positive family history of thyroid malignancy and one patient $(0.8 \%)$ had a history of radiotherapy. Ninety-three $(76.7 \%)$ patients had normal TFTs at the time of diagnosis. In the remainder, TFT results were compatible with hypothyroidism in 12 (9.9\%), subclinical hypothyroidism in nine $(7.4 \%)$, hyperthyroidism in three $(2.5 \%)$ and subclinical hyperthyroidism in four $(3.3 \%)$. In the whole cohort the median TSH level was 1.8 $\mu \mathrm{IU} / \mathrm{mL}$ but varied widely from completely surpressed to significantly elevated (0.06-100.0 $\mathrm{\mu IU} / \mathrm{mL})$. In 34 (28.1\%) of patients at least one of anti-TPO or anti-TG antibodies were positive. Serum calcitonin and thyroglobulin levels

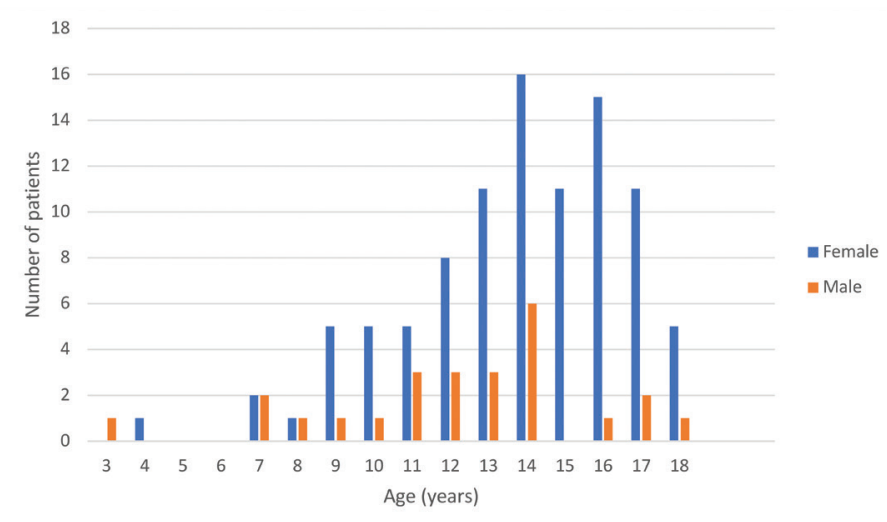

Figure 1. Age and sex distrubition of the patients were increased in one $(0.8 \%)$ and $43(35.5 \%)$ patients, respectively.

Median nodule size was 13 (5-55) $\mathrm{mm}$. Less than half of patients $(n=54 ; 44.6 \%$ ) patients had a single nodule. Other US findings were as follows: nodule structure was solid in $63(52.1 \%)$, cystic in eight $(6.6 \%)$, solid/cystic in 47 $(38.8 \%)$ and there was a calcificated area without evident nodule formation in three $(2.5 \%)$ patients; the nodule was hypoechoic in $67(55.4 \%)$, isoechoic in $34(28.1 \%)$ and hyperechoic in 20 (16.5\%) patients; blood flow was increased in $30(24.8 \%)$ patients; nodule margins were irregular in 31 (25.6\%) patients; and microcalcification and parenchymal heterogeneity were present in 35 (28.9\%) and $68(56.2 \%)$ patients, respectively.

Fifty-three patients $(43.8 \%)$ had multiple FNAs and 192 FNA results were evaluated. Fifty-eight FNA results were nondiagnostic with an overall non-diagnostic rate of $30.2 \%$. Initial FNA results of patients (including the first biopsy results of the patients with multiple FNA) were as follows; nondiagnostic in $18(14.9 \%)$, benign in 62 (51.2\%), AUS/ FLUS in $19(15.7 \%)$, FN/SFN in nine $(7.4 \%)$, SFM in seven $(5.8 \%)$ and malignant in six $(5.0 \%)$ patients. Final FNA results of patients (considering the most recent FNA results in patients with multiple FNA) were insufficient material in one $(0.8 \%)$, benign in $68(56.2 \%)$, AUS/FLUS in $22(18.2 \%)$, FN/SFN in $12(9.9 \%)$, SFM in $10(8.3 \%)$ and malignant in eight $(6.6 \%)$ patients.

The thyroid council decided that nodules of 55 patients required surgery and follow-up of 39 of them was continued in our center. Surgery undertaken consisted of nodulectomy ( $n=2$; nodulectomy only performed in the early period of the study), lobectomy $(n=10)$, subtotal thyroidectomy $(n=5)$ and total thyroidectomy $(n=22)$. Among 39 patients the cytological diagnosis of differentiated thyroid cancer (DTC) was made in one of 12 patients with AUS, 4 of 8 patients with FN/SFN, 2 of 4 patients with SFM and 3 of 3 patients with malignancy. Among the patients with DTC the types were papillary carcinoma (PTC) in seven and follicular carcinoma in three after histopathological examination and diagnosis. The total malignancy rate was $10 \%(10 / 100)$ among the cases in whom thyroidectomies were performed in our center and whose histopathologic diagnosis were known (21 patients had surgical follow-up elsewhere). None of the ten patients with malignancy had a history of radiotherapy or history of thyroid malignancy in family. The median (range) largest thyroid nodule dimension in these cases with DTC was $12(5-48) \mathrm{mm}$. Only two cases had a nodule size $<10 \mathrm{~mm}$ (both $5 \mathrm{~mm}$ ) and FNA was planned due to the presence of microcalcification in these two patients. A 7 year old girl with congenital hypothyroidism 
who had been on levothyroxine treatment since postnatal day 27 was found to have a $13 \mathrm{~mm}$ nodule in follow up and was diagnosed with PTC. Her average TSH level all through 7 year period was $<2.5 \mathrm{ng} / \mathrm{dL}$ did not have gland enlargement in control US's till diagnosis. Individual clinical and ultrasonographic properties of patients with DTC is given in Table 1.

There were 35 patients with at least one non-diagnostic FNA result, either as an initial FNA result $(n=18)$ or after repeat FNA's of initially benign or indeterminate results. Their subsequent FNA results were as follows: nondiagnostic in one $(2.9 \%)$, benign in $22(62.8 \%)$, AUS in seven (20\%), SFN in four $(11.4 \%)$ and malign in one $(2.9 \%)$ patient.

When follow-up of 80 patients with at least one benign FNA result, either as an initial FNA result $(n=62)$ or repeat FNA of an initially non-diagnostic FNA $(n=14)$, AUB $(n=2)$ or FN/ SFN $(n=2)$ results was evaluated, in $15(18.7 \%)$ of the 80 patients' control biopsies there was evidence of progression, when evaluated by TBSRTC stage (AUS $n=9$, FN/SFN $n=3$, SFM $n=2$, malignant $n=1)$, while $22(27.5 \%)$ patients' control biopsies were benign and 43 (53.8\%) patients' follow-up US did not require repeat FNA. Five patients with indeterminate (AUS, FN/SFN or SFM) repeat FNA results were lost to follow-up or refused surgery. Consequently, four patients with an initial benign FNA among 75 patients with at least one benign result (excluding five patients lost to follow-up) had DTC after surgical excision and histological examination giving a $5.3 \%$ false negative rate.

In the follow-up of 31 patients with AUS, FNA was repeated in 13 patients (benign $n=4$, AUS $n=3$, FN/SFN $n=5$, SFM $\mathrm{n}=1$ ), nine patients had thyroidectomy and five patients were referred to adult endocrinology or were lost to follow- up. Two of the 15 patients operated in our hospital were diagnosed with PTC (Figure 2).

Risk factors for malignancy were evaluated among the 100 patients who were not referred on, did not quit follow-up or did not refuse surgery in whom DTC was present in 10 and the remainder $(n=90)$ were benign (Table 2$)$. TSH levels and nodule size were similar in both groups. Male gender, presence of HT, uninodularity, hypoechogenicity, increased blood flow, irregular margins, solid structure, microcalcification of the nodule and presence of abnormal cervical lymph nodes were found to be associated with malignancy. Parenchymal heterogeneity was found to be associated with benign nodules.

\section{Discussion}

In this study clinical, radiological and pathological findings of 121 children and adolescents with thyroid nodules were evaluated. The frequency of nodules increased and female dominance became evident with increasing age, especially after onset of puberty. Thyroid nodules are more common in women and their frequency increases with age. Female dominance can be explained by increased incidence of autoimmune thyroiditis, together with the influence of estrogen and progesterone on thyroid cells $(12,13)$.

Dyshormonogenesis, HT, Graves disease, iodine deficiency, history of radiotherapy and some genetic disorders are known to increase nodule development $(6,8)$. In this study, the vast majority of patients did not have any known thyroid disease or thyroid dysfunction, and only one patient had a history of radiotherapy. The fact that diagnostic US was requested according to the inspection and palpation

\begin{tabular}{|c|c|c|c|c|c|c|c|c|}
\hline \multirow[t]{2}{*}{ Case } & \multirow[t]{2}{*}{ Age } & \multirow[t]{2}{*}{ G } & \multirow[t]{2}{*}{ TD } & \multicolumn{3}{|c|}{ US findings of the nodule } & \multirow[t]{2}{*}{ FNA } & \multirow[t]{2}{*}{ Histopathological diagnosis } \\
\hline & & & & $\mathrm{L}(\mathrm{mm})$ & Echogenicity & MC & & \\
\hline 1 & 7 & $\mathrm{~F}$ & $\mathrm{CH}$ & 13 & Нypo & + & SFM & PTC, CS \\
\hline 2 & 8 & M & - & 21 & Нyро & - & Malignant & PTC, CS \\
\hline 3 & 10 & M & - & 48 & Iso & + & FN/SFN & FTC, invasive \\
\hline 4 & 13 & M & HT & 12 & Нypo & + & FN/SFN & PTC, DSS \\
\hline 5 & 13 & $\mathrm{~F}$ & HT & 12 & Нyро & - & FN/SFN & FTC, WD \\
\hline 6 & 13 & $\mathrm{~F}$ & - & 35 & Нyро & + & Malignant & PTC, CS \\
\hline 7 & 14 & $\mathrm{~F}$ & HT & 5 & Iso & + & FN/SFN & PTC, FS \\
\hline 8 & 14 & F & - & 10 & Нуро & - & AUS & PTC, FS \\
\hline 9 & 15 & $\mathrm{~F}$ & HT & 5 & Hyper & + & SFM & PTC, CS \\
\hline 10 & 16 & M & HT & 39 & Iso & - & Malignant & FTC, MI \\
\hline
\end{tabular}

G: gender, F: female, M: male, TD: thyroid disease, HT: Hashimoto’s thyroiditis, CH: congenital hypothyroidism, US: ultrasonography, L: length, MC: microcalcification, FNA: fine needle aspiration biopsy, FN/SFN: follicular neoplasm/suspicious for follicular neoplasm, SFM: suspicious for malignancy, AUS: atypia of undetermined significance, PTC: papillary thyroid carcinoma, FS: follicular subtype, DSS: diffuse sclerosing subtype, CS: classic subtype, FTC: follicular thyroid carcinoma, MI: minimal invasive, WD: well differentiated 
FNA competible with AUS ( $\mathrm{n}=31$ )

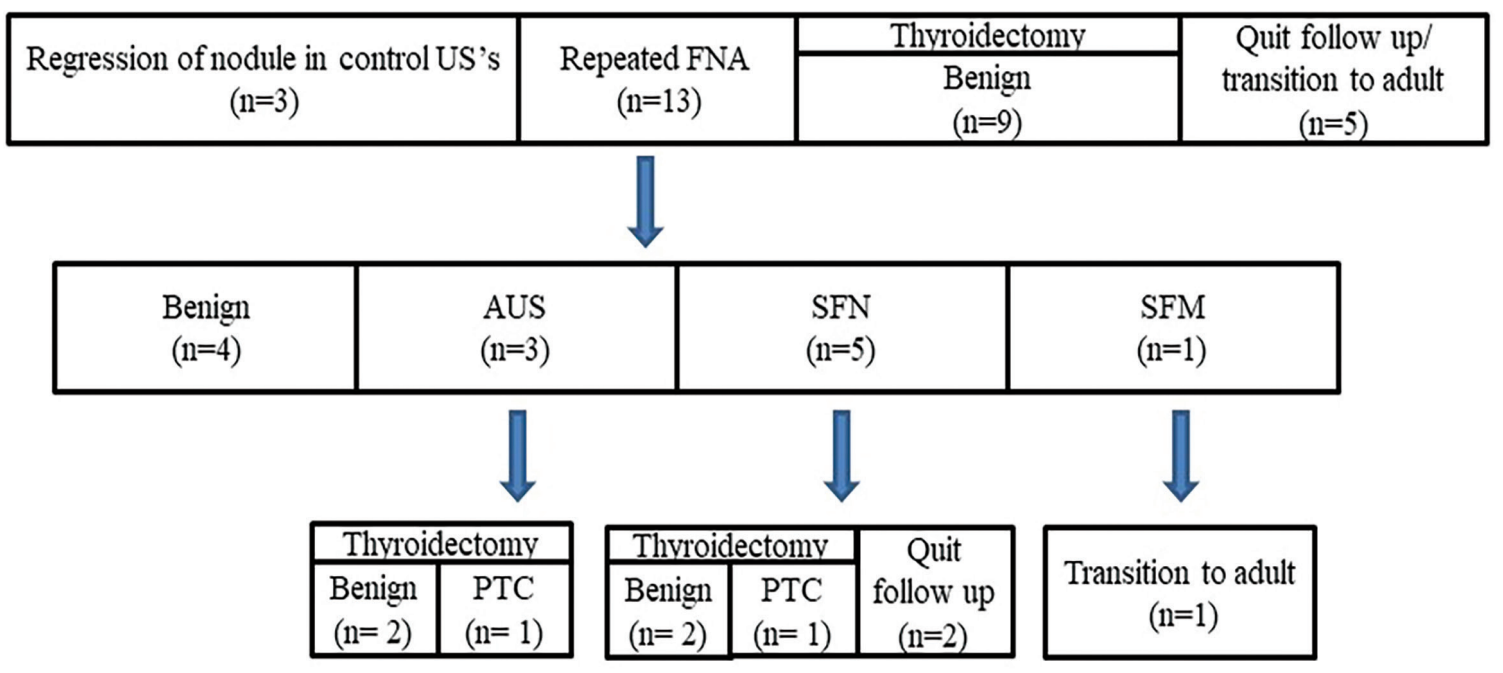

Figure 2. Follow up of patients with fine needle aspiration biopsies compatible with atypia of undetermined significance FNA: fine needle aspiration biopsy, AUS: atypia of undetermined significance, US: ultrasonography, SFN: suspicious for follicular neoplasm, SFM: suspicious for malignancy, PTC: papillary thyroid carcinoma

\begin{tabular}{|c|c|c|c|}
\hline & \multicolumn{2}{|l|}{ Total $^{1}(n=100)$} & \multirow[t]{2}{*}{$\mathrm{p}$} \\
\hline & Benign $^{2}(n=90)$ & Malignant $^{3}(n=10)$ & \\
\hline TSH level ( $\mu \mathrm{IU} / \mathrm{mL})$ & $1.82(0.2-100)$ & $1.55(0.7-5.3)$ & 0.82 \\
\hline Gender (male/female) & $18 / 72$ & $4 / 6$ & $<0.001$ \\
\hline Nodule size $(\mathrm{mm})$ & $12(5-55)$ & $12(5-48)$ & 0.74 \\
\hline Uninodularity $\mathrm{n}(\%)$ & $37(41.1)$ & $6(60.0)$ & $<0.001$ \\
\hline Solid structure n (\%) & $42(46.6)$ & $9(90.0)$ & 0.016 \\
\hline Hypoechogenicity n (\%) & $48(53.3)$ & $6(60.0)$ & $<0.001$ \\
\hline Increased blood flow n (\%) & $15(16.6)$ & $5(50.0)$ & 0.025 \\
\hline Irregular margin $n(\%)$ & $19(21.1)$ & $3(30.0)$ & $<0.001$ \\
\hline Microcalcification $\mathrm{n}(\%)$ & $20(22.2)$ & $6(60.0)$ & 0.02 \\
\hline Parenchymal heterogeneity n (\%) & $49(54.4)$ & $4(40.0)$ & $<0.001$ \\
\hline Abnormal cervical lymph nodes n (\%) & $4(4.4)$ & $3(70.0)$ & 0.02 \\
\hline Hashimoto thyroiditis n (\%) & $23(25.6)$ & $5(50.0)$ & $<0.001$ \\
\hline Increased thyroglobulin $\mathrm{n}(\%)$ & $32(35.9) 4$ & $4(40.0)$ & $>0.99$ \\
\hline \multicolumn{4}{|c|}{$\begin{array}{l}\text { 1Patients who quit follow up or refuse surgery were excluded. } \\
{ }^{2} \text { Patients with cytopathologic or histopathologic benign results. } \\
\text { 3Patients with histopathologic malignant results. } \\
{ }^{4} \text { Thyroglobulin result was missing in one patient. } \\
\text { TSH: thyroid stimulating hormone }\end{array}$} \\
\hline
\end{tabular}


findings in most of cases emphasizes the importance of holistic examination in pediatric practice.

A wide range of malignancy rate (6.6-56\%) has been reported for childhood thyroid nodules $(14,15,16)$. There may be overestimation in series of tertiary centres where patients with indeterminate and malignant FNA results are referred (16). Discordant results can also be explained by small sample sizes and the variation in inclusion criteria of the previous studies. Malignancy risk is underestimated in pediatric series which include cases up to the age of 21 and overestimated in series which limit inclusion to operated nodules $(15,17,18)$. The overall incidence of thyroid carcinoma among operated children with nodules was given as $26.2 \%$ in a review summarizing 16 studies including 1164 patients since 1960 (6). When we evaluated the malignancy rate among the operated cases only, the malignancy rate in our study (10/36, 25.6\%) was compatible with the literature.

FNA is a reliable method to assess the possibility of malignancy of a thyroid nodule and necessity for surgery. Its accuracy is $95 \%$ with $83 \%$ sensitivity, $92 \%$ specificity, $5 \%$ false negativity and $3 \%$ false positivity (19). Although FNA is a safe method and complications are very rare, it is an interventional process and patient selection should be made carefully. Which nodules should undergo FNA should be decided according to US findings. Adult guidelines, which primarily consider the size of the nodule as an indication for FNA and which do not recommend FNA for $a<1 \mathrm{~cm}$ nodule unless the patient is considered high risk with a history of ionizing radiation exposure or pathologic regional lymph nodes, have been applied to children and adolescents for a long time (20). However, children and adolescent demonstrate differences in pathophysiology and clinical presentation and the 2015 ATA guideline for children with thyroid nodules and DTC recommends using US features and clinical context rather than size alone to identify nodules that require FNA (7). It is notable that extended indications for FNA, considering US features and clinical context primarily, had already been in use in most pediatric endocrinology clinics, including ours. Thus, two patients with nodule sizes of $5 \mathrm{~mm}$ were directed to FNA because of microcalcifications within the nodule and were diagnosed with PTC.

Categorizing FNA results according to TBSRTC in children has equal accuracy, sensitivity and specificity as in adults $(5,21)$. Risk of malignancy in nondiagnostic samples in adults is very low, however it is not known if this holds true for children (22). Repeat of FNA at least three months after, is given as an option in the ATA guideline (8). In this study, FNA was repeated in all cases with nondiagnostic results and a malign result was found in one patient. However, this can not be given as malignancy rate of nondiagnostic results because nearly one third of the repeated FNA were compatible with AUS or SFN which have potential for malignancy.

Patients with benign FNA are followed-up with US after 6-12 months. Repeat FNA and/or lobectomy plus isthmusectomy is required if the nodule is growing or there are suspicious US findings (8). The probability of having a benign nodule on surgical excision is $90 \%$ in patients with one benign FNA and $98 \%$ in patients with at least two benign FNAs. Patients can be safely monitored without going to surgery with repetitive biopsies, unless clinical changes develop (23). There is a small but significant false negative rate with FNA (20). False negativity is increased in larger nodules and lobectomy is an option in patients with nodules over $>4 \mathrm{~cm}$ $(8,24)$. In this study, $17.5 \%$ of the 80 patients with initial benign FNA, had indeterminate cytology and one patient with a $12 \mathrm{~mm}$ nodule had malignant cytology on repeat FNA. The mean nodule size was $17 \pm 8 \mathrm{~mm}$ in patients with indeterminate cytology. False negativity in FNA is not specific to very large nodules. FNA should be repeated if there is increase in nodule size or there are specific US features, such as microcalcification.

Repeat FNA in indeterminate results is recommended as an option in adult guidelines that have also been used for children (20). Risk of malignancy in indeterminate nodules is higher in children ( $28 \%$ in AUS/FLUS and $58 \%$ in FN/ SFN) than in adults (5-15\% in AUS/FLUS and 15-30\% in FN/ SFN) $(25,26)$. Hence, the 2015 ATA Guideline for children recommends definitive surgery for indeterminate results (8). All follow up decisions for indeterminate nodules were made by the thyroid council directing FN/SFN and SFM results to surgery. AUS/FLUS results tended to be directed to surgery after 2015 and total the malignancy rate was 9\% (2 among 22 patients who weren't lost to follow up or refused surgery). Recently, Cherella et al (27) reported that $28 \%$ of nodules with AUS on initial FNA were benign on repeat FNA, while this rate was $31 \%$ in this study. Based on this data, repeat FNA may still be considered for AUS/FLUS cytology, however small number of cases in these studies suggest further investigation is warranted (2).

TSH has a major role on the proliferation and functioning of thyroid cell and persistently elevated TSH levels increase the risk of DTC formation (28). Even patients with a nodule and TSH levels in upper tertiles of reference range may have increased risk for malignancy (29). Mussa et al (30) showed that TSH levels of children with DTC were higher than children with benign nodules after excluding the ones already on levothyroxine treatment or the ones with hypo/ hyperthyroidism. However, its hard to documentate how 
long the patients' TSH levels had been over or within the upper tertile of the normal range. So that, in this study, none of the 10 patients with DTC had subclinical or overt hypothyroidism (six of them were already on levothyroxine) and TSH levels were similar in both groups even after excluding the patients with abnormal TSH levels from the benign group.

Primary congenital hypothyroidism due to dyshormonogenesis may have increased risk of developing goiter, thyroid nodules and malignancy. European Society for Pediatric Endocrinology recommends periodical neck US every 2 to 3 years in patients with goitrous dyshormonogenesis. Although poor compliance to treatment leading to persistently high TSH levels and presence of goiter are thought to be the possible causes, malignancy can develop despite adequate levothyroxine treatment in patients with dyshormonogenesis (31). Our patient with congenital hypothyroidism who developed PTC neither had high TSH levels nor goiter. Drut and Moreno (32) also reported a case of PTC in a five-year-old girl with congenital nongoitrous dyshormonogenetic hypothyroidism. Even if there is no goiter in patients with congenital hypothyroidism, thyroid nodules should be checked periodically with US.

HT is the most common inflammatory thyroid disease and is characterized by a wide range of morphological changes in the gland. Co-existence of DTC and HT has been reported in many publications $(33,34)$. However, it is not clear whether lymphocytic infiltration due to HT facilitates DTC formation or the immune response against the tumour initiates lymphocytic infiltration (28). Adult studies that have investigated the prevalence of HT among patients with DTC have reported a variable prevalence of 5-85\% (35). Our findings were compatible with the study of Hacıhamdioğlu et al (36) which reported HT prevalence as $45 \%$ (all with PTC) among 20 children with DTC. Older ages at diagnosis and smaller tumour sizes were also reported by them, and our findings support this. In a study focusing on malignancy risk among children with HT, risk of malignancy among nodules that required FNA was $25 \%$ while this was $17.9 \%(5 / 28)$ in our study, both of which indicate a higher malignancy prevalence than in nodules in the absence of HT (37).

US findings, such as hypoechogenicity, increased blood flow, irregular margins, solid structure, microcalcification of the nodule and presence of abnormal cervical lymph nodes, which were identified as malignancy risk factors in our cohort, are in keeping with previous studies which have reported these characteristics to be more common in malignant nodules $(38,39,40,41)$. Although hypoechogenicity and increased blood flow have high negative predictive value and high sensitivity, microcalcifications and presence of abnormal cervical lymph nodes have the highest specificity and positive predictive value and because of this, FNA is recommended for nodules with microcalcifications and abnormal lymph nodes, independent of nodule size (21). The two subcentimeter malignant nodules, both with microcalcifications and one with abnormal lymph nodes but without hypoechogenicity or increased blood flow in this study, supports the importance of this recommendation.

\section{Study Limitations}

The main limitations of this study were the small sample size and retrospective design of the study. Additionally, about $1 / 6$ of the patients' progress was unknown due to them being lost to follow-up, refusing surgery, or having surgery elsewhere, mostly because they had reached an age (16-18 years) and had applied to adult clinics.

\section{Conclusion}

There is a considerable malignancy risk of $10 \%$ in childhood thyroid nodules. Nodules $\geq 1 \mathrm{~cm}$ or $<1 \mathrm{~cm}$ with additional high-risk US findings, such as microcalcification or abnormal lymph nodes, should be directed to FNA. However, due to the $5.3 \%$ false negative rate in FNA, patients with benign FNA result should continue to be followed regularly and FNA should be repeated if their findings progress. Although the malignancy rate was not different in AUS/FLUS cases compared to the general sample of this study, due to the low number of cases, routinely repeating FNA before committing to surgery cannot be recommended in patients with AUS.

\section{Ethics}

Ethics Committee Approval: This study was approved by the University of Health Sciences Turkey, Ankara Dr. Sami Ulus Children Training and Research Hospital Specialty and Training Review Board with the decision number 2019/12.

Informed Consent: The need to obtain informed consent from the study participants was waived due to the study's retrospective nature.

Peer-review: Externally peer-reviewed.

\section{Authorship Contributions}

Surgical and Medical Practices: Selin Elmaoğulları, Şervan Özalkak, Semra Çetinkaya, İbrahim Karaman, Çiğdem Üner, Nilüfer Arda, Şenay Savaş-Erdeve, Zehra Aycan, Concept: Selin Elmaoğulları, Semra Çetinkaya, Şenay Savaş-Erdeve, Zehra Aycan, Design: Selin Elmaoğulları, Semra Çetinkaya, Şenay Savaş-Erdeve, Zehra Aycan, Data Collection or Processing: Selin Elmaoğulları, Şervan Özalkak, Şenay Savaş-Erdeve, Zehra Aycan, Analysis or Interpretation: 
Selin Elmaoğulları, Şervan Özalkak, Semra Çetinkaya, Şenay Savaş Erdeve, Zehra Aycan, Literature Search: Selin Elmaoğulları, Şervan Özalkak, Writing: Selin Elmaoğulları, Şervan Özalkak.

Financial Disclosure: The authors declared that this study received no financial support.

\section{References}

1. Silva de Morais N, Stuart J, Guan H, Wang Z, Cibas ES, Frates MC, Benson $\mathrm{CB}$, Cho NL, Nehs MA, Alexander CA, Marqusee E, Kim MI, Lorch JH, Barletta JA, Angell TE, Alexander EK. The Impact of Hashimoto Thyroiditis on Thyroid Nodule Cytology and Risk of Thyroid Cancer. J Endocr Soc 2019;3:791-800. Epub 2019 April 10

2. Bauer AJ. Thyroid nodules in children and adolescents. Curr Opin Endocrinol Diabetes Obes 2019;26:266-274. Epub 2019 July 31

3. Niedziela M, Korman E, Breborowicz D, Trejster E, Harasymczuk J, Warzywoda M, Rolski M, Breborowicz J. A prospective study of thyroid nodular disease in children and adolescents in western Poland from 1996 to 2000 and the incidence of thyroid carcinoma relative to iodine deficiency and the Chernobyl disaster. Pediatr Blood Cancer 2004;42:84-92. Epub 2004 January 31

4. Guth S, Theune U, Aberle J, Galach A, Bamberger CM. Very high prevalence of thyroid nodules detected by high frequency $(13 \mathrm{MHz})$ ultrasound examination. Eur J Clin Invest 2009;39:699-706. Epub 2009 July 16

5. Gupta A, Ly S, Castroneves LA, Frates MC, Benson CB, Feldman HA, Wassner AJ, Smith JR, Marqusee E, Alexander EK, Barletta J, Doubilet PM, Peters HE, Webb S, Modi BP, Paltiel HJ, Kozakewich H, Cibas ES, Moore FD, Jr., Shamberger RC, Larsen PR, Huang SA. A standardized assessment of thyroid nodules in children confirms higher cancer prevalence than in adults. J Clin Endocrinol Metab 2013;98:3238-3245. Epub 2013 June 06

6. Niedziela M. Pathogenesis, diagnosis and management of thyroid nodules in children. Endocr Relat Cancer 2006;13:427-453. Epub 2006 May 27

7. Haugen BR, Alexander EK, Bible KC, Doherty GM, Mandel SJ, Nikiforov YE, Pacini F, Randolph GW, Sawka AM, Schlumberger M, Schuff KG, Sherman SI, Sosa JA, Steward DL, Tuttle RM, Wartofsky L. 2015 American Thyroid Association Management Guidelines for Adult Patients with Thyroid Nodules and Differentiated Thyroid Cancer: The American Thyroid Association Guidelines Task Force on Thyroid Nodules and Differentiated Thyroid Cancer. Thyroid 2016;26:1-133. Epub 2015 October 16

8. Francis GL, Waguespack SG, Bauer AJ, Angelos P, Benvenga S, Cerutti JM, Dinauer CA, Hamilton J, Hay ID, Luster M, Parisi MT, Rachmiel M, Thompson GB, Yamashita S. Management Guidelines for Children with Thyroid Nodules and Differentiated Thyroid Cancer. Thyroid 2015;25:716-759. Epub 2015 April 23

9. Cibas ES, Ali SZ. The 2017 Bethesda System for Reporting Thyroid Cytopathology. Thyroid 2017;27:1341-1346. Epub 2017 November 02

10. Caturegli P, De Remigis A, Rose NR. Hashimoto thyroiditis: clinical and diagnostic criteria. Autoimmun Rev 2014;13:391-397. Epub 2014 January 18

11. Scappaticcio L, Trimboli P, Keller F, Imperiali M, Piccardo A, Giovanella L. Diagnostic testing for Graves' or non-Graves' hyperthyroidism: A comparison of two thyrotropin receptor antibody immunoassays with thyroid scintigraphy and ultrasonography. Clin Endocrinol (Oxf) 2020;92:169-178. Epub 2019 November 20
12. Manole D, Schildknecht B, Gosnell B, Adams E, Derwahl M. Estrogen promotes growth of human thyroid tumor cells by different molecular mechanisms. J Clin Endocrinol Metab 2001;86:1072-1077. Epub 2001 March 10

13. Wang K, Yang Y, Wu Y, Chen J, Zhang D, Liu C. The association of menstrual and reproductive factors with thyroid nodules in Chinese women older than 40 years of age. Endocrine 2015;48:603-614. Epub 2014 July 12

14. Altıncık A, Demir K, Abacı A, Böber E, Büyükgebiz A. Fine-needle aspiration biopsy in the diagnosis and follow-up of thyroid nodules in childhood. J Clin Res Pediatr Endocrinol 2010;2:78-80. Epub 2011 January 29

15. Roy R, Kouniavsky G, Schneider E, Allendorf JD, Chabot JA, Logerfo P, Dackiw AP, Colombani P, Zeiger MA, Lee JA. Predictive factors of malignancy in pediatric thyroid nodules. Surgery 2011;150:1228-1233. Epub 2011 December 06

16. Gupta A, Ly S, Castroneves LA, Frates MC, Benson CB, Feldman HA, Wassner AJ, Smith JR, Marqusee E, Alexander EK. A standardized assessment of thyroid nodules in children confirms higher cancer prevalence than in adults. The Journal of Clinical Endocrinology \& Metabolism 2013;98:3238-3245

17. Group CPTNS. The Canadian Pediatric Thyroid Nodule Study: an evaluation of current management practices. J Pediatr Surg 2008;43:826-830.

18. Kapila K, Pathan SK, George SS, Haji BE, Das DK, Qadan LR. Fine needle aspiration cytology of the thyroid in children and adolescents: experience with 792 aspirates. Acta Cytol 2010;54:569-574.

19. Sakorafas GH. Thyroid nodules; interpretation and importance of fineneedle aspiration (FNA) for the clinician - practical considerations. Surg Oncol 2010;19:e130-139. Epub 2010 July 14

20. Cooper DS, Doherty GM, Haugen BR, Kloos RT, Lee SL, Mandel SJ, Mazzaferri EL, McIver B, Pacini F, Schlumberger M, Sherman SI, Steward DL, Tuttle RM. Revised American Thyroid Association management guidelines for patients with thyroid nodules and differentiated thyroid cancer. Thyroid 2009;19:1167-1214. Epub 2009 October 29

21. Mussa A, De Andrea M, Motta M, Mormile A, Palestini N, Corrias A. Predictors of Malignancy in Children with Thyroid Nodules. J Pediatr 2015;167:886-892.e881. Epub 2015 July 15

22. Cibas ES, Ali SZ. The Bethesda System for Reporting Thyroid Cytopathology. Thyroid 2009;19:1159-1165. Epub 2009 November 06

23. Oertel YC, Miyahara-Felipe L, Mendoza MG, Yu K. Value of repeated fine needle aspirations of the thyroid: an analysis of over ten thousand FNAs. Thyroid 2007;17:1061-1066. Epub 2007 October 04

24. McCoy KL, Jabbour N, Ogilvie JB, Ohori NP, Carty SE, Yim JH. The incidence of cancer and rate of false-negative cytology in thyroid nodules greater than or equal to $4 \mathrm{~cm}$ in size. Surgery 2007;142:837. 844; discussion 844.e831-833. Epub 2007 December 08

25. Monaco SE, Pantanowitz L, Khalbuss WE, Benkovich VA, Ozolek J, Nikiforova MN, Simons JP, Nikiforov YE. Cytomorphological and molecular genetic findings in pediatric thyroid fine-needle aspiration. Cancer Cytopathol 2012;120:342-350. Epub 2012 May 19

26. Baloch ZW, LiVolsi VA, Asa SL, Rosai J, Merino MJ, Randolph G, Vielh P, DeMay RM, Sidawy MK, Frable WJ. Diagnostic terminology and morphologic criteria for cytologic diagnosis of thyroid lesions: a synopsis of the National Cancer Institute Thyroid Fine-Needle Aspiration State of the Science Conference. Diagn Cytopathol 2008;36:425-437. Epub 2008 May 15

27. Cherella CE, Angell TE, Richman DM, Frates MC, Benson CB, Moore FD, Barletta JA, Hollowell M, Smith JR, Alexander EK, Cibas ES, Wassner AJ. Differences in Thyroid Nodule Cytology and Malignancy Risk Between Children and Adults. Thyroid 2019;29:1097-1104. Epub 2019 July 13 
28. Zirilli G, Salzano G, Corica D, Pajno GB, Mignosa C, Pepe G, De Luca F, Crisafulli G. Thyrotropin serum levels and coexistence with Hashimoto's thyroiditis as predictors of malignancy in children with thyroid nodules. Ital J Pediatr 2019;45:96. Epub 2019 August 08

29. McLeod DS, Watters KF, Carpenter AD, Ladenson PW, Cooper DS, Ding EL. Thyrotropin and thyroid cancer diagnosis: a systematic review and dose-response meta-analysis. J Clin Endocrinol Metab 2012;97:26822692. Epub 2012 May 25

30. Mussa A, Salerno MC, Bona G, Wasniewska M, Segni M, Cassio A, Vigone MC, Gastaldi R, Iughetti L, Santanera A, Capalbo D, Matarazzo P, De Luca F, Weber G, Corrias A. Serum thyrotropin concentration in children with isolated thyroid nodules. J Pediatr 2013;163:1465-1470. Epub 2013 August 27

31. van Trotsenburg P, Stoupa A, Léger J, Rohrer T, Peters C, Fugazzola L, Cassio A, Heinrichs C, Beauloye V, Pohlenz J, Rodien P, Coutant R, Szinnai G, Murray P, Bartés B, Luton D, Salerno M, de Sanctis L, Vigone M, Krude H, Persani L, Polak M. Congenital Hypothyroidism: A 20202021 Consensus Guidelines Update-An ENDO-European Reference Network Initiative Endorsed by the European Society for Pediatric Endocrinology and the European Society for Endocrinology. Thyroid $2021 ; 31: 387-419$

32. Drut R, Moreno A. Papillary carcinoma of the thyroid developed in congenital dyshormonogenetic hypothyroidism without goiter: Diagnosis by FNAB. Diagn Cytopathol 2009;37:707-709. Epub 2009 August 07

33. Lai X, Xia Y, Zhang B, Li J, Jiang Y. A meta-analysis of Hashimoto's thyroiditis and papillary thyroid carcinoma risk. Oncotarget 2017;8:62414-62424

34. Graceffa G, Patrone R, Vieni S, Campanella S, Calamia S, Laise I, Conzo G, Latteri M, Cipolla C. Association between Hashimoto's thyroiditis and papillary thyroid carcinoma: a retrospective analysis of 305 patients. BMC Endocr Disord 2019;19(Suppl 1):26.
35. Lee JH, Kim Y, Choi JW, Kim YS. The association between papillary thyroid carcinoma and histologically proven Hashimoto's thyroiditis: a meta-analysis. Eur J Endocrinol 2013;168:343-349. Epub 2012 December 06

36. Hacıhamdioğlu B, Oçal G, Berberoğlu M, Savaş Erdeve S, Camtosun E, Kocaay P, Fitoz S, Ceyhan K, Dindar H, Yağmurlu A, Kır M, Unal E, Siklar Z. The evaluation of thyroid carcinoma in childhood and concomitance of autoimmune thyroid disorders. J Pediatr Endocrinol Metab 2014;27:901-908. Epub 2014 May 24

37. Corrias A, Cassio A, Weber G, Mussa A, Wasniewska M, Rapa A, Gastaldi R, Einaudi S, Baronio F, Vigone MC, Messina MF, Bal M, Bona G, de Sanctis C. Thyroid nodules and cancer in children and adolescents affected by autoimmune thyroiditis. Arch Pediatr Adolesc Med 2008;162:526-531. Epub 2008 June 06

38. Joseph-Auguste J, Lin L, Demar M, Duffas O, Molinie V, Sulpicy C, Dorival MJ, Luxembourger O, Sabbah N. Epidemiologic, Clinical, Ultrasonographic, and Cytological Features of Thyroid Nodules in Predicting Malignancy Risk: A Retrospective Study of 442 French AfroCaribbean Patients. Int J Endocrinol 2020;2020:4039290. Epub 2020 April 23

39. Lyshchik A, Drozd V, Demidchik Y, Reiners C. Diagnosis of thyroid cancer in children: value of gray-scale and power doppler US. Radiology 2005;235:604-613. Epub 2005 March 17

40. Leboulleux S, Girard E, Rose M, Travagli JP, Sabbah N, Caillou B, Hartl DM, Lassau N, Baudin E, Schlumberger M. Ultrasound criteria of malignancy for cervical lymph nodes in patients followed up for differentiated thyroid cancer. J Clin Endocrinol Metab 2007;92:35903594. Epub 2007 July 05

41. Grani G, D’Alessandri M, Carbotta G, Nesca A, Del Sordo M, Alessandrini S, Coccaro C, Rendina R, Bianchini M, Prinzi N, Fumarola A. Grey-Scale Analysis Improves the Ultrasonographic Evaluation of Thyroid Nodules. Medicine (Baltimore) 2015;94:e1129. Epub 2015 July 15 